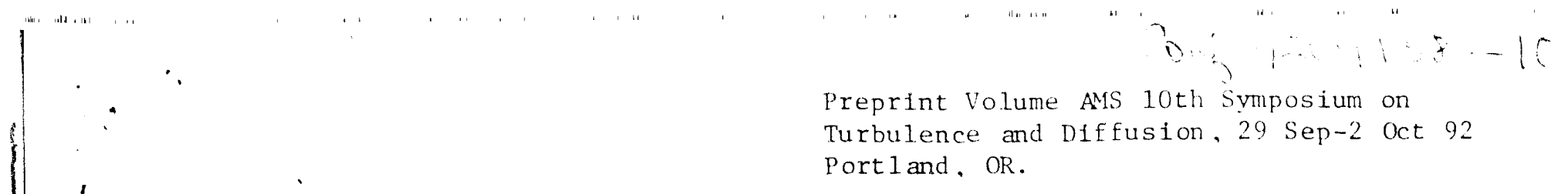

\title{
A CONVECTIVE DRAG THEORY FOR SURFACE FLUXES
}

\author{
Roland B. Stull \\ Boundary Layer Research Team, Dept. of Atmospheric \& Oceanic Sci. \\ University of Wisconsin, Madison, WI 53706 USA \\ FG02-92ER 61361
}

\section{TRANSPORT SUPERPOSITION}

For a convective mixed layer, it is hypothesized that turbulent transport by large convective thermals is quasi-independent of the transport by smaller-size shear-generated eddies in the surface layer; however, there is a superposition of both processes.

Evidence for such a superposition of independent processes is in the mean wind $(M)$ profile (Fig 1c). Above the surface layer and below the top of the mixed layer $\left(z_{i}\right)$ the wind speed $\left(M_{M L}\right)$ is constant with height $(z)$ yet is subgeostrophic, suggesting that surface friction information is being transported evenly throughout the mixed layer (Fig 1b). Furthermore, this propagation of friction information must be independent of mechanical turbulence in the surface layer, because the log wind profile does not extend above the surface layer (Fig 1C).

It is suggested that each quasi-independent process obeys the following transport equation for flux across an interface:

$\overline{w^{\prime} s^{\prime}}=w_{T}^{\prime} \cdot\left(S_{\text {below }}-S_{\text {above }}\right)$

where $w_{T}$ is a transport velocity characteristic of the physical process, and $\overline{w^{\prime} s^{\prime}}$ is the vertical kinematic flux of variable $S$ at the surface. For shear-driven turbulence, $w_{T}=C_{D} \cdot M$, which yields the well-known bulk-aerodynamic formulae, for surface-layer drag coefficient $C_{D}$. It is proposed that $n_{T}=C_{*} \cdot w_{*} *$ for convection, where $C_{*}$ is a mixed-layer drag coefficient, and $w_{*}$ is the convective velocity scale.

Fig 1. (a) The geostrophic wind $(G)$ is given as an external forcing. (b) Nonlocally-acting coherent thermal structures transport frictional information from the surface and distribute it more-or-less evenly throughout the mixed layer. (c) Mechanical shear-driven eddies dominate in the surface layer, resulting in a log wind profile that is limited to a small vertical domain.

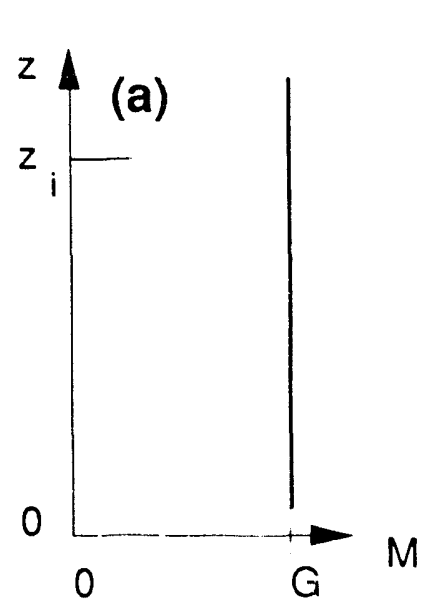

CONF-9209158--10

DE93 004037
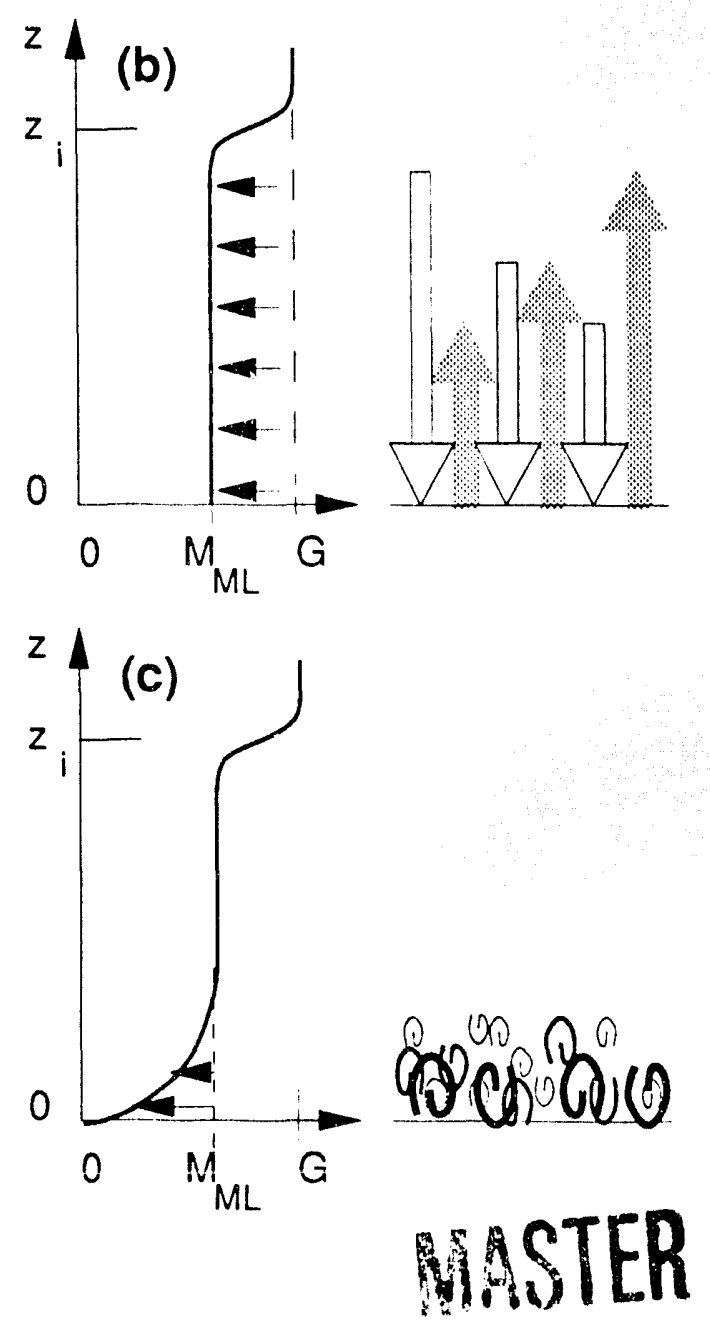

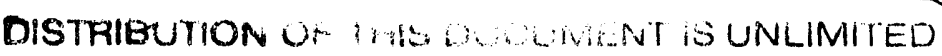




\section{FREE CONVECTION}

When this latter relationship is plugged into the interface-flux expression (1), the surface momentum flux can be parameterized after a little manipulation (Stull, 1992) by:

$u_{*}^{2}=b_{D} \cdot w_{B} \cdot M_{M L}$

the heat llux by:

$\overline{w^{\prime} \theta_{s}^{\prime}}=b_{H} \cdot w_{B} \cdot\left(\theta_{\text {skin }}-\theta_{M L}\right)$

and the moisture flux by:

$\overline{w^{\prime} r^{\prime}}=b_{H} \cdot w_{B} \cdot\left(r_{\text {skin }}-r_{M L}\right)$

where the $b$ parameters are empirical "convective drag cocfficients".

In expressions (2) - (4), $u_{*}$ is the friction velocity, $q$ is potential temperature, $r$ is mixing ratio, subscript $M L$ denotes in the interior of the mixed layer, and subscript skin denotes the characteristics of the underlying solid or liquid surface.

A buoyancy velocity scale is defined by

$w_{B} \approx\left[\left(g / \theta_{v}\right) \cdot z_{i} \cdot\left(\theta_{v \operatorname{skin}}-\theta_{v M L}\right)\right]^{1 / 2}$

where $q_{v}$ is virtual potential temperature, and $g$ is gravitational acceleration.

Using 11 days of data from the BLX83 field experiment in Oklahoma (Stull and Eloranta, 1984), the convective drag coefficients are empirically found to be:

$$
\begin{aligned}
& b_{D}=0.00183 \\
& b_{H}=0.0005
\end{aligned}
$$

\section{VERIFICATION AGAINST INDEPENDENT DATA}

These parameterizations for free convection are validated using independent data from the Australian Koorin field experiment (Clarke and Brook, 1979). They published 30 days of data beginning on $15 \mathrm{July}$ 1974 (winter), each of which had a convective mixed layer. Quasi-steady mixed layers were selected by considering only those data between 1100 through 1700 local time. From ine rinaining daia, oniy those satisfying the free-convection criterion of $R_{*}>3$ were used, where the "buoyancy Richardson number" is defined by:

$R_{*}=\left(w_{B} / M_{M L}\right)^{2}$

This left 298 data points each representing half-hourly averages from all 30 days.

Forecasts made using (3) and (7) are compared with Koorin observations in Fig 2. The mean error of $0.0073 \mathrm{~K} \cdot \mathrm{m} / \mathrm{s}$ is small compared to the mean flux value of $0 . .7 \mathrm{~K} \cdot \mathrm{m} / \mathrm{s}$. Thus, the empirical value (7) from BLX83 appears to in the correct order of magnitude for Koorin.

There is a noticeable trend with small fluxes being underpredicted and large fluxes overpredicted. This trend might be related to shear production of turbulence, which is not totally excluded from the observed data set. A parameterization that includes both effects is presented next

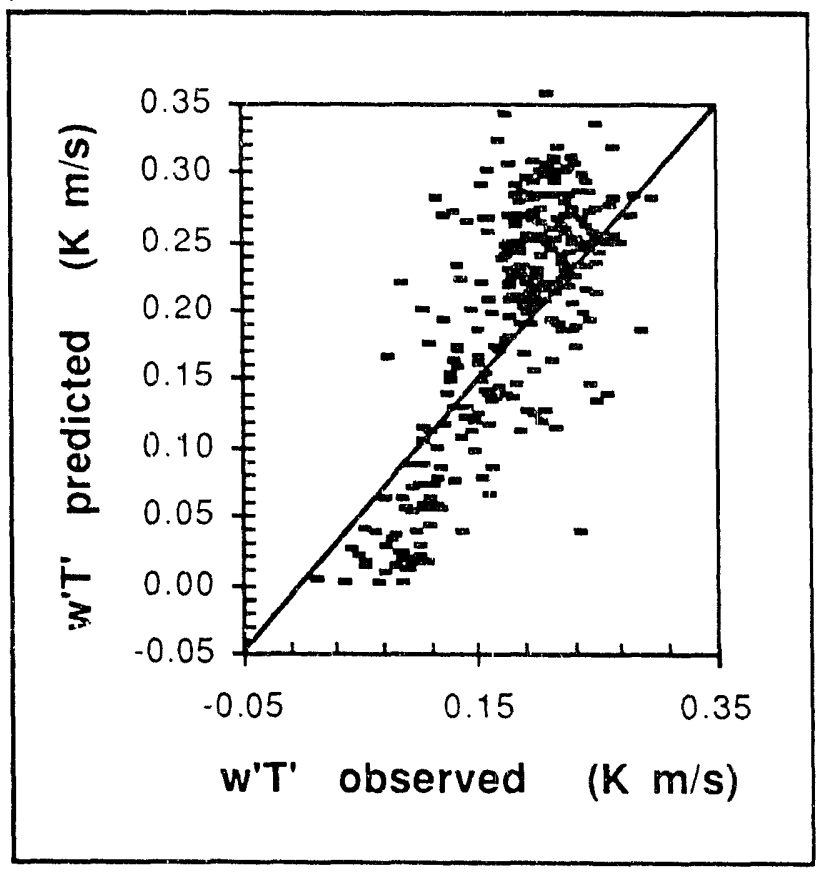

Fig 2.Data from the Koorin field experiment in Australia is used to verify the heat surface heat flux predicted assuming only the free-convective transport described by (3) and (7).

\section{MIXED CONVECTION}

Combining convective and shear processes in a linear superposition gives: 
$u_{*}^{2}=\left(C_{D M L} \cdot M_{M L}+b_{D} \cdot w_{B}\right) \cdot M_{M L}$

and

$\overline{w^{\prime} \theta^{\prime}}=\left(C_{H M L} \cdot M_{M L}+b_{H} \cdot w_{B}\right) \cdot \Delta \theta$

where $C_{D M L}$ and $C_{H M L}$ are drag coefficients that are neither a function of surface roughness nor stability, and which are applied to the mean wind in the mixed layer.

Roughness is not a factor because (9) and (10) use mixed layer winds rather than surface layer winds. Stability is not a factor because it is explicitly included in the convective drag terms in (9) and (10).

Fig 3 shows predicted vs. observed heat flux from the BLX83 experiment assuming only free convection (i.c., using eqs $3 \& 7$ ). These points show a similar trend as for Koorin data in Fig 2.

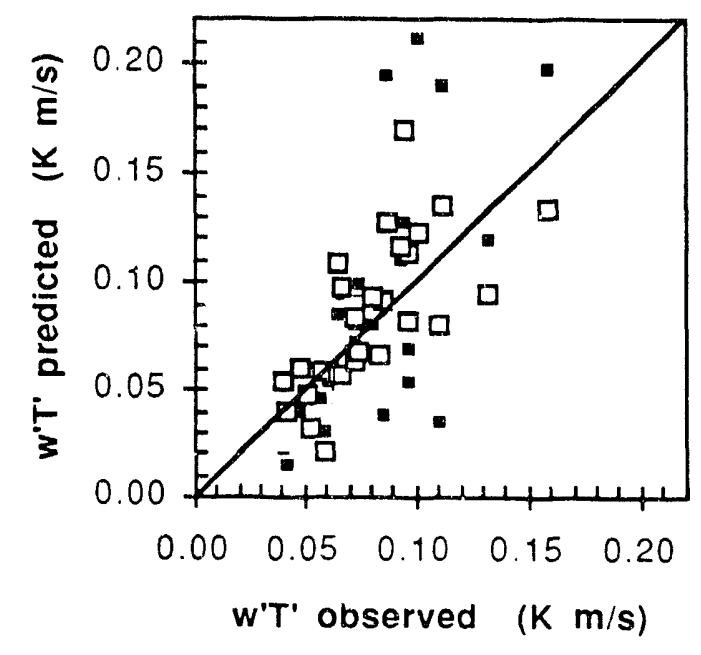

Fig 3For BLX83 data, the solid points show predictions made assuming free convection only (eqs $3 \& 7$ ). The open points assume mixed convection, using eqs (10) and (12), and are a better fit.
When $(10)$ is used instead of (3), the verification in Fig 3 is much better, and the trend is removed. Because a portion of the flux is now explained by mechanical transport, the values of the empirical parameters for the convective portion must obviously be reduced. For the BLX83 data set, the best empirical parameters for (9) and (10) are:

$$
\begin{array}{ll}
C_{D M L}=0.0035 & b_{D}=0.0007 \\
C_{H M L}=0.001 & b_{H I}=0.00025
\end{array}
$$

\section{SIGNIFICANCE}

Weather and climate forecast models that might not have fine enough grid spacing to resolve the surface layer can utilize mixed-layer quantities in the parametcrization proposed here.

The parameterizations do not fail in the limit $r f$ zero mean wind. This makes it applicable to situations such as in the tropical western Pacific Ocean, where traditional drag laws are suspected of underestimating the heat and moisture fluxes from the ocean. Investigators in the TOGA-COARE field project will have an opportunity to test this hypothesis.

The form of the surface flux parameterizations presented here are very similar to convective mass flux parameterizations for the interior of mixed layers and cloud layers (Randall et al, 1992). Perhaps these two approaches can be combined into a unified theory.

Remote sensors such as satellite-borne radiometers or ground-based high-spectral-resolution interferometer spectrometers (HIS) can use radiometric data to estimate fluxes. For example, the HIS instruments can measure mixed-layer depth, temperature and moisture, while co-located downward-looking radiometers can measure the surface skin temperature and moisture. This is sufficient data to determine heat and moisture fluxes using (3) and (4) on days of free convection.

Stull (1992) shows how surface-layer scaling variables such as the Obukhov length and Richardson number can be calculated from mixed layer observations using the equations presented above. These relationships can be used with existing similarity theory to estimate many turbulence characteristics and mean profiles in the surface layer. Thus, radiometric measurements are sufficient to calculate quantities such as $T K E$ and its dissipation rate, $e$, vertical velocity variance profiles, etc.

Finally, instead of tuning surface-layer parameterizations to attempt to make them work in the mixed layer, the approach taken here is to determine the relevant physics causing transport in the mixed layer, and then develop an appropriate parameterization based on that physics. For free convection, the 
parameterization utilizes the concept of nonlocal, nondiffusive transport associated with large, coherent, thermal structures in the convective mixed layer.

Acknowledgements. This research was supported by the U.S. Department of Energy under grant DEFG02-92ER61 361.

\section{References}

Clarke, R.H. and R.R. Brook, 1979: The Koorin Experiment, Atmospheric Boundary Layer Data of Tropical Savannah Land. Bureau of Meteorology, Australian Government Publishing Scrvice, Canberra, ISBN-()-642-()1484-1. 359pp.

Randall, D.A., Q. Shao and C.-H. Moeng, 1992: A second-order bulk boundary layer model. J. Atmos. Sci., (in press).

Stull, R.B., 1992: A convective drag theory for surface fluxes. (Submitted to $J$. Atmos. Sci.)

Stull, R.B. and E.W. Eloranta, 1984: Boundary-Layer Experiment 1983. Bull. Amer. Meteor. Soc., 65, 45()-456.

\section{DISCLAIMER}

This report was prepared as an account of work sponsored by an agency of the United States This report was pere the United States Government nor any agency thereof, nor any of their employees, makes any warranty, express or implied, or assumes any legal liability or responsibility for the accuracy. completeness, or usefulness of any information, apparatus, product, or process disclosed, or represents that its use would not infringe privately owned rights. Reference herein to any specific commercial product, process, or service by trade name, trademark, manufacturer, or otherwise does not necessarily constitute or imply its endorsement, recommendation, or favoring by the United States Government or any agency thereof. The views and opinions of authors expressed herein do not necessarily state or reflect those of the United States Government or any agency thereof. 

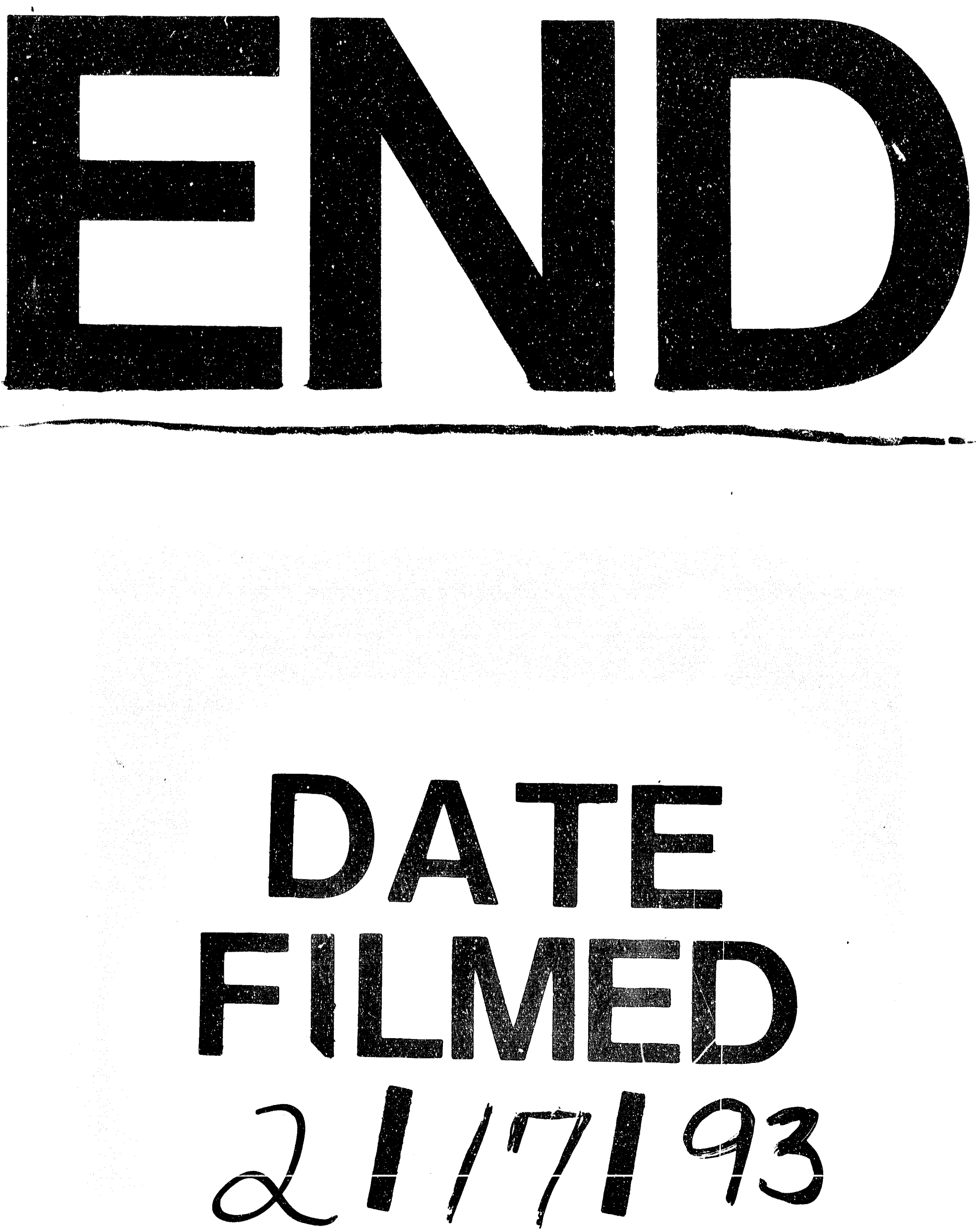


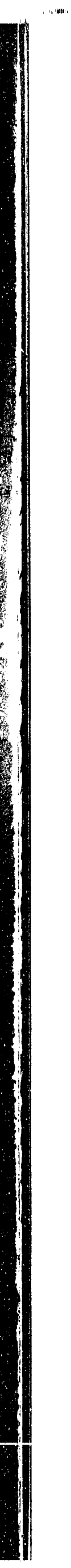

